\title{
Leis, Serpentes e Baratas: análise reconstrutiva da sobrevivência das formas de fundamentos do Direito Moderno e seus efeitos na realidade brasileira
}

\author{
Laws, Snakes and Cockroaches: reconstructive analysis of the survival of the \\ forms of foundations of Modern Law and its effects on the Brazilian reality
}

\author{
Francisco Cardozo Oliveira ${ }^{1}$ \\ Nancy Mahra de Medeiros Nicolas Oliveira ${ }^{2}$ \\ ${ }^{1}$ Centro Universitário de Curitiba (UniCuritiba), Curitiba, PR, Brasil \\ ${ }^{2}$ Associação dos Magistrados do Trabalho da 9a Região (AMATRA IX), Curitiba, PR, Brasil
}

\begin{abstract}
Resumo: O texto elabora uma relação entre reconstrução normativa, retomada do pensamento de Hegel, e sobrevivência das formas (Nachleben), elaborada por Aby Warburg, para mostrar como os fundamentos do direito continuam sujeitos às formas de pensamento de fundamentos jusnaturalistas e positivistas. Percorre a análise de uma perspectiva de aproximação entre direito e arte. Em registro crítico, tendo em perspectiva a realidade social e jurídica brasileira, são elaborados o diagnóstico dos retornos das formas de fundamento no direito e o modo como eles atuam para obstaculizar o salto intersubjetivo que possa manter aberta a possibilidade de ampliação de direitos.
\end{abstract}

Palavras-chave: Sobrevivência de Formas. Formas de Pensamento. Fundamentos do Direito.
Abstract: The text draws a relationship between normative reconstruction, taken from Hegel's thought and survival of forms (Nachleben), elaborated by Aby Warburg, to show how the foundations of law remain subject to thought forms of jusnaturalist and positivist foundations. The analysis goes through a perspective of approximation between law and art. In critical analysis, taking into account the Brazilian social and legal reality, is elaborated the diagnosis of the returns of the forms of foundation in the law and the way in which they act to obstruct the intersubjective leap that can keep open the possibility of extension of rights.

Keyword: Survival of Forms. Thought Forms. Foundations of Law.

Recebido em: 25/06/2018

Revisado em: 12/02/2019

Aprovado em: 28/02/2019 


\section{Introdução}

A análise envolve esforço reconstrutivo que permita estabelecer o confronto entre os fundamentos do direito e as necessidades de transformação da vida em sociedade, tomando-se em perspectiva a ideia de sobrevivência de formas e a relação entre direito e arte. De forma sintética, a análise trata da relação inescapável entre o direito e a evolução da vida social ao longo da história. Procura-se evidenciar o que está implicado na relação entre fundamentos do direito e mudança social, influenciado pela constelação de valores e de conflitos que acompanha a trajetória da vida em sociedade; trata-se, portanto, de avaliar a sobrevivência (Nachleben) de valores e de ideias na sistematização do direito, desde a modernidade até os dias atuais.

O problema a ser enfrentado diz respeito à identificação daquilo que se manifesta como sobrevivência das formas de pensamento na estrutura dos fundamentos do direito da modernidade, no confronto entre jusnaturalismo e positivismo, e seus desdobramentos na realidade brasileira contemporânea.

O desenvolvimento da análise se inicia definindo os contornos da relação entre direito e arte, mediante um paradigma reconstrutivo relacionado à ideia de sobrevivência. Na sequência, busca-se estabelecer a sobrevivência de formas de fundamentos jusnaturalistas no direito e seu contexto social. Na parte final, a análise trata da sobrevivência de formas de fundamentos positivistas no direito, vista em perspectiva de relação com a estrutura social e econômica. No decorrer da análise, deve ficar evidenciado o que na sobrevivência de formas nos fundamentos do direito surge relacionado aos conflitos, que se materializam na realidade da vida em sociedade, em especial no caso do Brasil, e seus efeitos em face das necessidades de realização de direitos e de efetivação da justiça.

A justificativa da análise emerge da necessidade de mensuração do alcance da capacidade do direito de adaptar-se às mudanças sociais confrontado com a sobrevivência de formas de fundamentos, de um lado ligados aos anseios mais elementares da trajetória de construção fraterna 
da humanidade no mundo e, de outro, capturados por obstáculos que retardam no tempo a realização da justiça.

Utiliza-se um método dialético e crítico, e nesse sentido ele próprio reconstrutivo, com apoio em pesquisa bibliográfica e documental, que ganha sentido na medida em que se desenvolve a reflexão.

\section{Os Pressupostos da Relação entre Direito e Arte: a sobrevivên- cia de formas e o paradigma reconstrutivo}

A ideia de sobrevivência de formas, que percorre a análise, coloca em perspectiva a relação entre direito e arte e o modo como, nessa relação, ao longo da história, se cristalizaram ideias que deram sentido à vida em sociedade. A relação entre direito e arte, que tenha como relevante o problema da sobrevivência das formas, implica uma analise de caráter normativo em dois momentos: o primeiro voltado para a compreensão do paradigma reconstrutivo e da ideia de sobrevivência de formas na arte; o segundo, relacionado ao desdobramento do paradigma reconstrutivo e da sobrevivência de formas nos fundamentos do direito.

\subsection{O Paradigma Reconstrutivo e a Ideia de Sobrevivência de Formas na Arte}

Para estabelecer a relação entre o paradigma reconstrutivo e a ideia de sobrevivência de formas é preciso compreender os termos do esforço metodológico de reconstrução; dessa compreensão poderá emergir a articulação com a ideia de sobrevivência de formas.

A premissa de reconstrução normativa adquire sentido no contexto de desenvolvimento da teoria crítica. Em Hegel, a ideia de reconstrução surge relacionada ao problema de estabelecer uma racionalidade antipositivista, capaz de romper com o imediato, e permitir a reflexão, inclusive sobre o modo como se estrutura o conceito e sua relação com o mundo e a coisa. $\mathrm{O}$ esforço reconstrutivo, consequentemente, contempla uma dimensão histórica e fenomenológica de assimilação da relação entre teoria e evolução social. Trata-se, nesse sentido, de estabelecer o tempo 
histórico em que se afirma a conexão da teoria e do conceito com sua realização na vida em sociedade. Na Fenomenologia do Espírito Hegel utiliza a ideia de rememoração para enfatizar que o espírito que adquire consciência-de-si conserva, ao mesmo tempo, seu ser-aí, sua historicidade; a rememoração permite ao espírito recomeçar sua formação de um novo patamar que não se esgota nele mesmo (HEGEL, 2014, p. 530). O que Hegel enfatiza é o devir que não se deixa aprisionar na identidade do conceito, que sempre está imerso na equivocidade de sentidos. Assim, uma reconstrução normativa se justifica na medida em que se debruça sobre a historicidade do conceito cuja potencialidade busca afirmar-se ao longo do tempo na estrutura da vida em sociedade. Nessa direção, Axel Honneth (2009) defende a necessidade de refazer o caminho percorrido pela teoria crítica, mediante uma reconstrução normativa, que tenha como relevante os desdobramentos na sociedade dos conflitos em torno da luta por reconhecimento de direitos. Trata-se de recuperar na teoria crítica, a perspectiva do social, que teria sido negligenciada na trajetória construída desde os pressupostos estabelecidos por Max Horkheimer nos anos 1930. O paradigma reconstrutivo reafirmado por Axel Honneth, de acordo com Marcos Nobre, opera em dois níveis: o primeiro, de esforço reconstrutivo de modelos teóricos, e o segundo, voltado para os resultados obtidos com a reconstrução, de modo a reforçar os pressupostos de uma crítica que esteja ancorada nos desdobramentos da vida social; coloca-se para o paradigma reconstrutivo, de acordo com Marcos Nobre (2013, p. 11-54), a necessidade de um diagnóstico do tempo presente orientado para e pela emancipação.

Tomando em conta a questão dos fundamentos do direito, a reconstrução normativa deve permitir estabelecer no tempo, de um lado, a promessa no passado de realização de direitos e de justiça e, de outro, o resultado que pode ser diagnosticado no presente, no sentido de potencial de emancipação da pessoa. Assim, no contexto de evolução histórica da modernidade e da pós-modernidade, a reconstrução normativa permite fixar o alcance das promessas de fundamentos jurídicos jusnaturalistas e positivistas e seus efeitos em face da virada linguística, que provocou desdobramentos filosóficos de fundamentação e de justificação de operacionalidade sistêmica e de efetividade de direitos. A reconstrução norma- 
tiva, nesse sentido, permite estabelecer um momento de emergência e de consolidação de fundamentos no direito, e nisso reside o resgate histórico, e um momento de mensuração de resultados, que se dá no tempo presente e sua abertura para o futuro; no percurso, observa-se o modo como uma concepção teórica de fundamentos no direito se confronta com os conflitos na construção da socialidade.

O potencial metodológico da reconstrução normativa não pode ser compreendido tomado o modelo da cientificidade positivista de separação entre sujeito e objeto, e o consequente subjetivismo que lhe é inerente; o método não constitui o a priori separado da reflexão; é preciso seguir o curso da reconstrução para perceber nela o modo como o resgate fenomenológico do alcance e dos limites dos pressupostos dos fundamentos de sustentação do sentido do ordenamento jurídico ganha relevo ao longo do tempo.

\subsection{Sobrevivência e a Premissa de Reconstrução em Torno dos Funda- mentos do Direito}

O esforço de reconstrução permite identificar o modo como a sobrevivência das formas de fundamentos do direito retorna na passagem do tempo e na evolução histórica da modernidade e da pós-modernidade que, nesse sentido, constituem os limites da análise a ser desenvolvida.

A ideia de sobrevivência ganha relevância na arte como modo de explicação da transformação e do resgate de formas de expressão e de pensamento, de sentidos e de valores cristalizados na história da humanidade no mundo. A rememoração, por outro lado, constitui uma distinção de sobrevivência determinante para a construção de subjetividades e a constituição de sentidos para a evolução da vida social. O que sobrevive, nesse sentido, pode ser concebido por uma vertente antropológica e por outra psicanalítica. Na vertente antropológica, Aby Warburg formulou os termos da ideia de sobrevivência (Nachleben) que se manifesta nas formas de pensamento e de concepção de imagens e sua expressão na arte; ele procurou responder ao questionamento do modo como se originam as expressões linguísticas e as formas de imagens, assim como elas são armazenadas e sedimentadas na memória e, finalmente, como retornam 
como novas manifestações e exteriorizações no tempo; o percurso da resposta considera os desdobramentos nas imagens e na figuração de formas cristalizadas na história da humanidade; é nesse sentido que Aby Warburg (2015) observa que a Antiguidade influenciou o Medievo mediante o redespertar da linguagem gestual patética, típica da arte antiga, que ele define como a fórmula de emoções (Pathosformeln): a sobrevivência de uma forma de expressão, que está cristalizada na trajetória da humanidade e que, mediante uma espécie de rememoração dessa figuração do humano, ressurge transformada; e nesse ressurgimento, ao mesmo tempo em que resgata o passado, abre janelas para o futuro que se manifesta no presente. Justificava-se, desse modo, a tentativa de Aby Warburg de organização de um Atlas de reproduções e de inventário do que poderia ser qualificado como pré-formações antigas que influenciaram o Renascimento italiano e que, na forma de ressurgimento transformador, continuam a contribuir para a formação de estilos na modernidade, e mesmo agora na pós-modernidade.

No campo da narrativa, Erich Auerbach (2004) analisa o que ele denomina elemento retardador no qual, por meio de uma interpolação, o poeta, ao mesmo tempo em que não fornece ao leitor toda a extensão do presente, mantém em suspenso a tensão recorrendo ao que foi vivido no passado; a narrativa, portanto, também se apoia em uma construção que coloca em movimento a tensão elaborada na relação entre passado e presente.

$\mathrm{Na}$ vertente psicanalista, o resgate do passado pode ser visto na perspectiva de um efeito a posteriori que está ilustrado por Freud (2010, p. 13-160) no caso do "Homem dos Lobos", no qual o trauma recalcado opera o retorno na forma de um pesadelo e passa a ser compreendido como elemento integrante da vida do sujeito. O retorno do reprimido, tomado do pensamento freudiano, é apropriado pela arte surrealista para expressar um compromisso com a libertação do sujeito e com o amor.

Mas o que se mostra mais produtivo, em termos de efeito a posteriori (Nachträglichkeit), é a analogia elaborada por Hal Foster (2014, p. 47-48), no sentido de que a vanguarda histórica na arte se constitui pelo que ele denomina de complexa alternância de futuros antecipados e passados reconstruídos, ou seja, um efeito que não pode ser mensurado por 
um esquema simples de causa e efeito, origem e repetição; o caráter significativo da obra de arte nunca é plenamente compreendido em um momento inicial e imediato; ele opera como um trauma elaborado que retoma efeitos no futuro. Assim, também no efeito a posteriori se manifesta uma espécie de formas de sobrevivência que atuam por meio de retornos no tempo histórico.

Como se observa, existe uma espécie de complementaridade entre os pressupostos metodológicos de reconstrução normativa e a premissa de sobrevivência de formas: ambas operam a partir do modo como uma determinada ideia, ou pensamento, se incorporou à trajetória de evolução da vida social. Para o que interessa nessa análise, é possível afirmar que a reconstrução normativa resgata as formas de fundamentos que sobrevivem e retornam no direito; mas não é o resgate simplesmente o que interessa; em uma perspectiva crítica, interessa avaliar o que a sobrevivência de formas, nos fundamentos jurídicos, contempla de ampliação ou de limitação de titularização de direitos na atualidade. Nesse sentido, importa para a análise que a ideia de sobrevivência permita evidenciar o sentido dos retornos dos fundamentos e formas de pensamento jusnaturalistas e positivistas no direito; nessa direção pode emergir o modo como o sistema jurídico procurou preservar sua integridade sistêmica, ao longo da modernidade e mesmo na pós-modernidade, confrontado com os conflitos, riscos e incertezas na evolução da vida em sociedade.

\section{Jusnaturalismos, Mitos e Serpentes: o eterno retorno do con- flito, da incerteza e da miséria}

A ordenação do direito incorpora o que nela se cristaliza como formas de sobrevivência de fundamentos consolidados ao longo do tempo. Resulta necessário, desse modo, identificar aquilo que se cristalizou na ordenação do direito ao longo da história. Embora recorrente nas análises elaboradas à luz da crítica construída pela corrente interdisciplinar de análise do direito e da literatura, Antígona, de Sófocles, permite demonstrar aquela que pode ser a principal sobrevivência de forma de fundamentos e de pensamento no direito que retorna e, portanto, serve ao propósito 
de uma reconstrução normativa, que é a contraposição entre lei positiva e justiça; na articulação dessa contraposição se manifesta outra desdobrada entre o racional, o mágico e o mítico. Quando Creonte acusa Antígona de desobedecer à lei, ela responde invocando a justiça e a equidade representada pela deusa Diké; se houve desobediência, diz Antígona, ela se deu em relação às normas divinas, não escritas, inevitáveis. Como diz François Ost (2005, p. 205), em comentário à Antígona, o apelo a um direito ideal revela toda a sua força quando as leis positivas, imunizadas em relação aos princípios e à equidade, mostram-se injustas e opressivas.

A relevância conferida à deusa Diké, na fala de Antígona, confere importância aos valores de equilíbrio que devem ser perseguidos pela justiça; a deusa Diké, filha de Zeus e de Themis, aparece associada na mitologia grega à ideia de prevalência da razão; o equilíbrio do justo possibilitado pela razão precisava ser velado pela divindade, que dispensava punição severa à injustiça; na relação entre justiça e injustiça se mantém a tensão entre o racional e o mítico. Como lembra Alasdair C. Macintyre (2001, p. 230), Diké significa a ordem do universo, de forma que surge a dificuldade de estabelecer o alcance do justo na ordem do governo dos homens e, ao mesmo tempo, na ordem cósmica, onde reinam os deuses; a transgressão do justo (dikaiosunê) implica discussão e discordância sobre o alcance da ordem e da violação; pode residir nessa dúvida, a opção da cultura ocidental pelo culto a Themis como a deusa da Justiça, liga à retidão da norma.

Considerado que a contraposição entre lei positiva e justiça opera no limite da razão e do mito, a tensão que se configura retorna ao longo do tempo nas formas de pensamento e de fundamentação do direito, a exemplo do que ocorre com o jusnaturalismo.

Convém observar o modo como, no jusnaturalismo, a razão e o mito atuam para delimitar o lugar da lei e da justiça; a análise dessa questão pode ser feita em duas perspectivas: a primeira, ligada ao jusnaturalismo de base teológica, em que a lei natural se desdobra para enfrentar os mitos e afirmar a prevalência de uma justiça divina e imutável; a segunda, em que a razão predomina nos fundamentos do direito em busca da ordem e da paz no mundo em convulsão. 


\subsection{Matemática, Mito e Causalidade: o jusnaturalismo como refúgio do mundo}

Os fundamentos do direito natural podem ser analisados de várias perspectivas; de um modo geral, o direito natural está ligado à ideia de fundamento último de validez e de obrigatoriedade das normas e de justiça. Na Ética a Nicômaco, Aristóteles trata da distinção entre o justo natural e o justo que decorre da lei; Tomás de Aquino, na Suma Teológica, distingue três espécies de leis: lei eterna (a ordenação divina do mundo), lei natural (princípios divinos que o homem conhece porque participa da natureza divina - a questão da justiça) e a lei positiva (direito positivo) (leis humanas que derivam das necessidades do homem na vida em sociedade) (Tratado da Justiça). Tomás de Aquino retoma a filosofia de Aristóteles, de moderação e prudência, de justiça, fins últimos, necessidades e condições sociais, para reafirmar que existe uma ordem no mundo que para ele, numa visão teológica, resulta de um Deus ordenador; o homem, por natureza, está ordenado para os fins, para a virtude e para a justiça. O jusnaturalismo de fundamento teológico busca estabelecer uma passagem entre as leis divinas e as leis positivas ditada pelo homem na ordenação da vida em sociedade.

A afirmação dos fundamentos jusnaturalistas do direito, contudo, se confunde com a luta do cristianismo contra as formas de concepção mítica do mundo que povoavam o Medievo. Na afirmação do racionalismo e dos valores cristãos Martin Lutero teve que confrontar o retorno de profecias da antiguidade pagã; enquanto Martin Lutero sustentava a onipotência de Deus, os míticos manejavam a astrologia para afirmar a fatalidade cómica nos destinos da humanidade; como afirma Aby Warbug (2015, p. 138), a cultura italiana do Renascimento revitalizou em imagens e textos profecias pagãs que misturavam elementos heterogêneos de racionalismo e de mitologia, de matemática calculista e de augúrio profético; segundo ele, o cristianismo se viu obrigado a combater essas práticas misteriosas sobreviventes de religiosidade pagã e suas formas de superstição futurologista. Em meio a essa batalha, a matemática acaba apropriada, tanto pela astrologia como pelo racionalismo, para explicar a causalidade dos eventos e seus efeitos no mundo. Como diz Aby Warburg (2015, p. 151), 
“[...] a matemática, a ferramenta mais refinada da força de abstração do pensamento, juntou-se ao temor aos demônios, a forma mais primitiva da causalidade religiosa".

Encontrar uma solução para o problema da causalidade confrontava racionalismo e misticismo: de um lado, o cristianismo tentando afirmar a prevalência de um Deus ordenador, cuja ordem se refletia na ação racional do mundo, mediada pelo direito natural; de outro, a sobrevivência de crenças proféticas na defesa de uma causalidade cosmológica, que regia o futuro da humanidade; de um lado e de outro, a matemática é instrumentalizada para fundamentar uma relação lógica ou mística entre causas e efeitos dos eventos. Aby Warburg (2015, p. 245-246), inclusive, lembra a simbologia bíblica da serpente associada ao pecado original; o cristianismo, diz ele, lutou contra o culto pagão à serpente. O mito da serpente está ligado ao sofrimento e a uma forma de justificação da causalidade dos fenômenos da natureza; ou, como diz Aby Warburg (2015, p. 242-243), a serpente é o símbolo da imortalidade e do renascimento diante da doença e da morte e, desse modo, ela permanece na memória e abre espaço para o caminho que vai da devoção à reflexão e, consequentemente, à modernidade.

O direito não passou imune à questão da causalidade e sua oscilação entre o místico e o racional. Também para o direito se tratou de transformar os mitos e a idolatria em fundamentos racionais de lei e justiça. Assim, os fundamentos teológicos do jusnaturalismo, em meio à luta entre racionalismo e misticismo, tiveram de racionalizar a causalidade da ordem da justiça no mundo. Um ideal de justiça divida e inscrita no mundo substituiu o mito da serpente como símbolo da vida eterna que sempre retorna.

A causalidade no direito, ligada ao problema da ordem do justo e as incertezas que ela provoca, pode ser tomada como um elemento aglutinador, capaz de fazer emergir o modo como a forma de pensamento jusnaturalista elabora os fundamentos do direito e seus retornos. É bem provável que a questão da causalidade, que até hoje surge envolta em dúvidas e que atravessa os fundamentos do direito desde, por exemplo, a relação entre fato e norma, até seus reflexos na responsabilidade civil e na teoria 
do crime, constitua um dos elementos centrais na ordenação do direito e na titularização de direitos.

Em face das incertezas sobre o destino do homem no futuro, que não deixa de estar ligado às questões da causalidade, o jusnaturalismo de base teológica buscou refúgio no idealismo de uma natureza imutável e de valores absolutos capazes de fornecer os elementos indispensáveis à ordenação do direito. Enquanto não se afirmava o primado da razão sobre o profético e o místico, o direito natural se restringe a um conjunto de valores abstratos que sustentam a ordenação do direito no mundo, nesse sentido, conforme esclarece Norberto Bobbio (2016), sem um compromisso de efetividade; exemplo dessa dificuldade pode ser constatado no desenvolvimento da história dos direitos humanos, em que, conforme ressaltam Oliveira e Oliveira (2014, p. 398-422), o compromisso com a efetividade dos direitos se restringe a enunciação de caráter declaratório. Diante das incertezas sobre o futuro da ação do homem no mundo, o jusnaturalismo teológico faz a defesa de um ideal de vida boa, imune de dúvidas, que pode ser sustentado sem os riscos dos conflitos.

A reconstrução normativa dos fundamentos teológicos do direito natural de base teológica serve para evidenciar o retorno das formas de pensamento que lhe são características como a defesa da natureza imutável e de uma moralidade que está acima do direito positivo.

Sobre o problema do retorno do jusnaturalismo e suas implicações religiosas Norberto Bobbio (2016, p. 38-39), olhando para a realidade da Itália, assinala que ele se manifesta quando os mecanismos operativos do ordenamento jurídico não se mostram eficazes para fazer a distinção entre lei justa e lei injusta, ou seja, o retorno se dá na mesma dimensão da tragédia de Antígona; nessa situação, diz Norberto Bobbio (2016, p. 38-39), passa a ser justificado um apelo ao direito natural; aceita-se a justificação do justo a partir de valores supremos.

Justamente nessa linha pode ser enquadrada a proposta de Alasdair MacIntyre (2013, p. 513-526), que, depois de criticar a incapacidade da modernidade de formular as bases de um compromisso moral, faz o ordenamento jurídico operar a partir do que ele denomina de compreensão de valores decorrentes das práticas na vida comunitária. 
Assim, na atualidade, não deve causar espanto um retorno do jusnaturalismo de fundamento religioso e idealista, no momento mesmo em que se reafirmam novas formas de religiosidade; o perigo que vem com esse retorno é de o direito, assim como a mística dos crentes pós-modernos, estar reduzido ao jogo do ritualismo; nesse contexto, que inclui a realidade brasileira, ganha sentido a mística da astrologia que, como bem anotou Theodor W. Adorno (2008), mobiliza sentimentos e alimenta a lógica do consumo na sociedade de massa, sem a promessa de efetividade dos direitos e com toda a sorte de efeitos em termos de esvaziamento da política e de formas de totalitarismos.

\subsection{O Mundo em Convulsão, a Miséria e a Paz do Jusnaturalismo Racionalista}

Quando Hugo Grotius (2004) sustentou que o direito existe mesmo que Deus não existisse, operou-se uma transição de paradigmas: a razão passa a ser o fundamento do jusnaturalismo. A passagem do jusnaturalismo de base teológica para o jusnaturalismo de fundamento racional evidencia o propósito de conferir estabilidade aos fundamentos do direito, no contexto de uma realidade mergulhada em conflitos que não alcançou estabilidade; as questões colocadas por Hugo Grotius traduzem a esperança de paz em uma realidade em que sucedem os conflitos, as revoluções e as guerras.

Não é mais o caso, também, de sustentar a primazia da natureza como fundamento último da ordenação do direito; se antes a natureza podia ser vista como o lugar em que reinava a paz e a harmonia, agora ela se revela ameaçadora para a vida humana. Como diz Norberto Bobbio (2016), rompeu-se o mito da natureza benéfica. No Leviatã de Thomas Hobbes, a natureza é sinônimo de violência e de força. Segundo Carlo Ginzburg (2014, p. 13-32), o pensamento de Thomas Hobbes articula o surgimento do Estado e o medo, a começar pelo nome do Leviatã, retirado do livro de Jó, que representa um animal gigantesco e indomável; de certo modo, o mito do Leviatã substitui o da serpente; mas o que é mais intrigante, segundo Carlo Ginzburg, é que Thomas Hobbes associa o surgimento da religião ao medo e dai deriva que também o Estado somente 
se consolida pelo medo que cobra reverência e sujeição; o medo sujeitaria as pessoas ao controle inevitável do Estado e a proteção que ele oferece contra a natureza indomável. Consequentemente, a obediência à lei é alcançada mediante o medo em face da ameaça representada pela violência da natureza. Como sustenta Paolo Grossi (2010), o imperativo do jusnaturalismo racionalista é o de formular um desenho jurídico absolutamente purificado da história, que promova a abstração das misérias do fático. Para as incertezas e os conflitos, que se manifestam na realidade, o jusnaturalismo racionalista contrapõe uma fundamentação abstrata e conceitual para o direito; busca-se segurança e estabilidade nas relações jurídicas em um mundo em convulsão.

Permanece, contudo, a questão de fundamentar os direitos naturais e, ao mesmo tempo, indicar o modo como os direitos ganham sentido na vida em sociedade. Nessa perspectiva, Domenico Losurdo (1998, p. 8992) afirma que a crítica de Hegel ao jusnaturalismo não significa, necessariamente, uma repulsa, mas a compreensão de que a dimensão de direitos inalienáveis, como a liberdade, precisa ser vista não mais no contexto de um estado da natureza, mas como resultado do processo histórico que envolve o desenvolvimento do próprio ordenamento jurídico e do homem; desse modo, os direitos naturais adquirem determinação histórica e social, de forma que o direito à liberdade, por exemplo, não pode ser visto fora do contexto histórico da vida em sociedade. Mas essa questão, segundo Norberto Bobbio (2016, p. 208), aponta um problema mais profundo para o direito natural: a distinção entre justo e injusto e, portanto, do que é e do que não é um fato natural. Permanece, portanto, o desacordo que retorna: o justo e o injusto em face da lei e da ordem.

Seguindo o pensamento de Norberto Bobbio (2016, p. 244), o retorno do jusnaturalismo mesmo na sua concepção racionalista, se opera sempre que ocorre uma revolta contra o formalismo e a percepção de injustiças a partir da aplicação da lei; diz ele que sempre, em momentos de crises, que se coloca a revolta dos fatos contra a lei, emerge a necessidade de apelar para a tradição do direito natural, em que almejada uma visão mais ampla das fontes do direito, que não dependeria apenas da vontade do legislador, mas de uma consideração objetiva dos fatos e do movimento de indivíduos e grupos em sociedade. 
Se ao longo da modernidade o positivismo se cristalizou como fundamento do direito, o formalismo que ele encerra, abriu oportunidade para a sobrevivência e o retorno de um jusnaturalismo que, embora não possa mais estar diretamente atrelado a fundamentos teológicos, não deixa de apelar para uma ordem distinta daquela observada pelo direito positivo.

De certo modo, na atualidade, a querela entre regras e princípios e a crítica ao principialismo discricionário, especialmente no Brasil, no sentido que lhe empresta Lênio Luiz Streck (2008), estão enredadas nos retornos do jusnaturalismo propiciados pelo positivismo formalista; trata-se da única forma de retorno possível, no momento, enquanto a configuração da economia capitalista não assimila uma virada efetivamente intersubjetiva, em que a titularidade dos direitos surja da existencialidade que se consolida na presença do outro.

$\mathrm{Na}$ medida em que na realidade brasileira se manifesta a miséria da desigualdade, o retorno do jusnaturalismo, que se opera como revolta ao formalismo, busca o refúgio da abstração dos princípios e seu correlato descompromisso com a efetividade de direitos.

\section{Positivismos, Burocratização da Vida e Baratas: a exclusão naturalizada}

Tratando da concepção formal de Justiça, Norberto Bobbio (2016, p. 104) afirma que a defesa da legalidade para os positivistas serve para distinguir atos jurídicos e não jurídicos; ele ressalta que não se trata de uma defesa legalista da justiça, porque a legalidade não serve para formular juízos sobre justo e injusto. Mas, o próprio Norberto Bobbio (2016, p. 71) não deixa de reconhecer que a tarefa da filosofia do direito é a de minar o lago artificial em que se mantém o sistema positivo do ordenamento jurídico.

Não é difícil estabelecer uma relação entre a artificialidade que o positivismo confere aos fundamentos do direito e a burocratização da vida que se consolida na modernidade. Essa correlação pode mais facil- 
mente ser objetivada se levado em conta que a sociedade moderna é uma sociedade jurídica, no sentido do que sustenta Pietro Barcellona; diz ele que na modernidade, e mesmo na sociedade contemporânea, a construção da socialidade se manifesta como relação jurídica; o contrato e o direito de propriedade constituem um princípio organizativo de relação recíproca entre indivíduos singulares; para o indivíduo insolado, a sociedade surge da trama de contratos e de direitos de propriedade; contudo, diz Pietro Barcellona (2003, p. 71-82), se referindo a Hans Kelsen e Max Weber, afirmar o primado da lei e da racionalidade jurídica, não permite negligenciar os riscos dos conflitos, na medida em que a defesa da universalidade da regra jurídica somente se torna possível no contexto de coexistência da multiplicidade de valores que conduz a um paradoxo: promove a atomização e o individualismo de um lado e, de outro, mantém a tensão do risco permanente de desordem, que, por sua vez, reclama um chamado a unificação de todos em torno da evolução social.

A consolidação do positivismo exigiu a construção de um Estado capaz de impor pela força a mediação dos conflitos latentes na realidade social, de modo a prevenir o risco constante da desordem. A burocratização do Estado e das organizações atuou, nesse sentido, para limitar a liberdade prometida pelo primado formalista da lei.

$\mathrm{Na}$ estrutura formalista do direito moderno, que assegura a consolidação do positivismo, com efeitos na pós-modernidade, se manifesta um duplo paradoxo, que pode ser visto como desdobramento daquele referido por Pietro Barcellona; o primeiro eixo desse paradoxo se manifesta na promessa da ordem jurídica de assegurar a liberdade confrontada com os limites do mundo dominado por organizações impessoais e pela burocracia; o segundo, se manifesta na promessa da industrialização e da tecnologia de ampliação de direitos, cuja dinâmica resulta em formas de exclusão.

Em torno desses paradoxos se articulam os retornos das formas de pensamento positivistas que, por maior que seja a pretensão de racionalidade, não estão livres do confronto com mitos e crenças. 


\subsection{O Guardião da Lei, o Mundo das Organizações e a Promessa de Liberdade da Modernidade}

Enquanto o jusnaturalismo precisou confrontar os místicos e os profetas para afirmar uma causalidade racional em torno da justiça, o positivismo, no contexto de consolidação do mundo moderno, esteve confrontado com o alcance da liberdade; afinal de contas, o primado da lei genérica e abstrata que o positivismo sustenta está diretamente relacionado com a perspectiva de conferir liberdade de valores e de ações aos indivíduos na vida em sociedade.

Ocorre que a liberdade não tem uma componente exclusivamente individual e singular; ela reclama um encontro com o outro na vida em sociedade; e nesse encontro, uma vez pressuposto que cada indivíduo exerce a sua liberdade, resulta potencializado o risco de conflito que somente a lei pode dar solução; assim, a lei que confere liberdade ao mesmo tempo está encarregada de limitá-la; em última instância o alcance da liberdade é o segredo que a lei guarda e que precisa ser desvendado. Esse paradoxo está ilustrado nos romances de Kafka em várias passagens. No conto "Diante da lei" (1991), o mistério burocrático da lei se revela em toda a intensidade; diante dos porteiros que guardam a lei, o camponês espera anos a fio para entrar; ele envelhece a espera da oportunidade de estar diante da lei; estando no fim da vida pergunta uma vez mais ao porteiro que guarda a lei porque ninguém quis entrar e, então, vem a resposta final: a lei estava a espera dele e apenas dele. Só no final da vida se revela o paradoxo que a lei guarda: o de estar o tempo inteiro disponível, mas, ao mesmo tempo, encerrada e inacessível a quem mais necessita dela.

Essa dupla face da lei, de disponibilidade e inacessibilidade, está espelhada no processo de burocratização que caracteriza o desenvolvimento da sociedade moderna.

A concepção de ação social de Max Weber (2009), que se define por um elemento relacional e outro racional serve para explicar o modo como se orientam as linhas de conduta individual diante do aumento da complexidade da vida moderna. Está em jogo a construção da subjetividade da pessoa em face do mundo burocratizado. Na sociedade moderna, o exercício da liberdade é mediado por uma ação racional. Como diz Karl 
Loewith (1983, p. 143-162), a racionalidade acompanha a liberdade de ação porque é uma liberdade a ser alcançada mediante o exercício da livre escolha dos meios adequados a um fim eleito e preestabelecido por valores ou significados de vida. O conhecimento metódico e a coisa como absoluto são os pressupostos da racionalização, que busca alcançar a unidade do mundo, mas a afirmação da unidade do mundo, como diz Theodor W. Adorno (2015, p. 33-86), reforça o caráter identitário em meio ao paradoxo do uno e do múltiplo. A ideia de ação social, desse modo, incorpora a dinâmica de um processo de adaptação da personalidade às exigências de racionalização organizacional do mundo moderno. Todavia, como assinala Karl Loewith (1983, p. 143-162), o próprio Max Weber vê o caráter irracional do processo de racionalização que se materializa na medida em que a impessoalidade e a burocracia das instituições envolvem o indivíduo, de modo que fins e valores da ação individual escapam ao seu controle.

O processo de racionalização que estrutura as organizações burocráticas na sociedade moderna engendra limites, e pode reduzir o potencial de exercício da liberdade. Assim, à dupla face da lei, que opera no registro disponível/inacessível, somam-se os limites para a ação do indivíduo diante da impessoalidade das organizações burocráticas; o resultado pode ser a impotência traduzida por Franz Kafka (2000) na metamorfose da pessoa em barata.

Se antes o mito da serpente traduzia a imortalidade e o que é perene na vida em sociedade, agora na modernidade e na pós-modernidade, a animalidade da barata simboliza a impossibilidade da reflexão no mundo dominado pelo que poderia ser denominado de mito da legalidade e seus efeitos no exercício da liberdade.

Os retornos das formas de pensamento positivistas se situam no registro das necessidades da economia capitalista de acelerar ganhos, mediante o uso da tecnologia, que cobra o seu preço na redução das possibilidades de salvaguarda da liberdade. No Brasil, não é incomum associar-se uma perspectiva de formalismo jurídico aos momentos de necessidade de superação das crises econômicas, que exige facilidades para os modos de acumulação de capital a custa da redução de liberdades e direitos. 


\subsection{Industrialização, o Mito da Tecnologia e a Proteção da Titularida- de de Direitos e suas Exclusões}

A racionalidade moderna engendrou mitos; um deles é a ideia de progresso e seu correlato, a invenção. $\mathrm{O}$ mito do progresso uniu interesses antagônicos porque continha uma promessa inclusiva pelo acesso à tecnologia. A conjugação entre ciência, inovação e progresso esteve confrontada com um horizonte de geração de benefícios propiciados pela tecnologia que precisava ter efeitos de melhoria na vida das pessoas. A ciência procurou atender as necessidades de acumulação de capital no processo de industrialização. A união pelo progresso, contudo, teve de confrontar revoltas populares mediante outro mito, o do inventor heroico que, como acentua François Jarrige (2009, p. 99-117), permitiu dissimular a complexidade do processo inventivo e as falhas nos estágios de inovação.

A positividade da maquinaria propiciou outro mito, o de que a automação dos processos industriais eliminaria o trabalho humano; contudo, como afirma Theodor W. Adorno (2015, p. 122-125), a máquina torna-se coisa depois que a consciência do construtor fez a relação entre a lógica matemática e a mecânica; assim, diz ele, o trabalho do construtor está materializado na máquina, que acaba esquecido para fazer emergir no mundo a correção matemática dos resultados e a causalidade mecânica. Reforça-se a premissa de que uma causalidade mecânica fundamenta o conhecimento que se esgota na objetividade da coisa; daí a mentalidade positivista enredada em perfis classificatórios, incapazes de dar conta das causalidades complexas da natureza e da vida em sociedade.

O incremento tecnológico parece não assegurar a ampliação da criatividade. $\mathrm{O}$ mito da serpente, que engendrava a causalidade e assegurava contra as ameaças da natureza cedeu lugar para o que Aby Warburg (2015, p. 253) qualifica de cultura das máquinas, que, na visão dele, destruiu o vínculo espiritualizado entre o homem e o mundo, com a consequente redução do espaço de reflexão e de simbolização.

No momento em que o mito do progresso confrontou-se com as possibilidades de esgotamento da natureza explorada como coisa, evidenciou-se a necessidade de repensar os fundamentos formalistas do direito; os limites colocados para a expansão de ganhos econômicos reduziram 
as possibilidades de ampliação de direitos e, desse modo, colocaram em risco os pressupostos da concepção de Estado Democrático de Direito. Consequentemente, os retornos da forma de pensamento positivista, embora tenham preservado o mito da legalidade, passaram a operar em outro registro: se antes a legalidade incluía e ampliava direitos, agora a sobrevivência das formas de pensamento positivista associa-se a técnicas de controle, de biopolítica e de exclusão. O direito se reduz a uma tecnologia de gestão e de governamentalidade, no sentido do que Michel Foucault (2001) denomina de dispositivos de controle. A irrupção de crises, de busca por ampliação de direitos, na sociedade pós-moderna, provoca um chamado à ordem que, no plano jurídico, se opera mediante a sobrevivência de formas de pensamento positivista que visa preservar posições de titularidades e ganhos financeiros.

Curiosamente, na atualidade, a sobrevivência de formas de pensamento positivista impõe-se no contexto em que a crença na legalidade parece esgotada, como é o caso do ordenamento jurídico brasileiro, em que um apelo à abstração dos princípios implode a lógica do sistema codificado herdado do direito moderno. A afirmação do princípio da legalidade, nesse contexto, surge reduzida ao ritual esvaziado de sentido que serve para manter estruturas de poder encarregadas de operar a redução de direitos e sistematizar as formas de controle da exclusão. Nesse sentido, a promessa de um encontro fraterno com o outro, proposto pela Revolução Francesa, como lembra Josiane Rose Petry Veronese (2016, p. 19-35), permanece irrealizada.

Desde uma perspectiva da globalização econômica, a sobrevivência de formas de pensamento positivista surge associada ao que Saskia Sassen (2016) qualifica de tendências de desterritorialização e de brutalidades do capitalismo financeirizado, cuja lógica de acumulação, produz formas de expulsão (desemprego, destruição ambiental, pobreza e desigualdades).

Os retornos de formas de pensamento positivistas, pelo menos na atualidade pós-moderna, estão compromissados com a potencialização de ganhos nos mercados, sem que esteja implicado, nesse compromisso, a 
ampliação de titularidade de direitos o que, em última análise, rompe com o mito do progresso que deu vida à modernidade.

\section{Conclusão}

Associar a ideia de sobrevivência de formas de pensamento à ideia de reconstrução normativa teve como objetivo analisar os retornos de positivismos e jusnaturalismos ao longo da consolidação da modernidade até a pós-modernidade, e seus efeitos na realidade brasileira. Tratou-se, portanto, de um resgate histórico e de consequente atualização; de apontar o que retorna e, ao mesmo tempo, indicar o modo como o que sobrevive contém indicativos de abertura para o novo ou de bloqueio para a evolução da socialidade.

Ao tomar a ideia de sobrevivência, no sentido do formulado por Aby Warburg, procurou-se estabelecer uma compreensão histórica dos fundamentos do direito que não estivesse limitada a uma sucessão de fatos no tempo ou presa a uma análise evolutiva, de cunho positivista ou idealista. A ideia de sobrevivência das formas que Aby Warburg pensou para as imagens e para arte contempla um desdobramento que não se esgota na positividade dos fatos, inseridos em um tempo linear da ação do homem no mundo; as sobrevivências lidam com a desorientação no tempo, o anacrônico, o que retorna como sintoma porque está inscrito na memória e na complexidade dos múltiplos efeitos dos fatos sujeitos às forças que interagem no contexto da vida em sociedade. Como diz Georges Didi-Huberman (2013, p. 51-57), na ideia de sobrevivência, Aby Warburg sintetizou a complexidade do tempo histórico ao reconhecer no mundo a existência de temporalidades específicas, em que a forma sobrevivente não sobrevive de modo total sobre as concorrentes; ela sobrevive como sintomas, fantasmas; desparece em um momento da história e surge em outro, quando não seria mais esperado, de modo diverso, mas sem perder a relação com a sua configuração no passado.

Em termos de sobrevivência e de retornos de fundamentos do direito, no contexto de evolução da modernidade, resulta importante assinalar, como síntese conclusiva, o alcance da sobrevivência e dos retornos e, na 
perspectiva de reconstrução histórica, daquilo que se cumpriu em termos de promessa do passado em relação ao presente.

É nesse sentido que se inscreve o problema colocado para análise.

Nessa perspectiva, a análise evidenciou que na evolução da modernidade os fundamentos do direito se mantiveram presos a retornos de formas de fundamentos jusnaturalistas e positivistas em que, no caso do jusnaturalismo sobrevivem os fantasmas e os sintomas do apelo idealista a justiça em contextos de injustiça e, no caso do positivismo, sobrevivem os mitos da legalidade e da igualdade, em meio a crises, desordens e desequilíbrios provocados pelas necessidades de renovação constante de formas de acumulação de ganhos na economia capitalista. No Brasil essa oscilação é mais intensa em face das crises decorrentes das desigualdades de acesso a bens e rendas; os retornos entre jusnaturalismo e positivismo se operam mediante fugas da realidade; ora caminha-se na direção de um idealismo da justiça dos princípios, ora deriva-se para a afirmação do princípio da legalidade e seu entorno de conceitos abstratos e atemporais.

Mas o que se revela mais importante, em termos de conclusão, é que, ao contrário do que parece acontecer com mais frequência na arte, em que a sobrevivência opera a abertura para o novo, no caso das formas de pensamento jusnaturalistas e positivistas o que se manifesta é a impossibilidade de transposição dos limites da modernidade; transformam-se os modos de acumulação da economia capitalista, sem a realização da promessa de ampliação de titularidades e de direitos, notadamente na realidade brasileira. Consequentemente, o salto intersubjetivo em direção ao outro, que constitui a pessoa, continua inviabilizado e não pode operar efeitos no ordenamento jurídico. Mas essa constatação não deve tranquilizar os vencedores da ordem da injustiça; não é certo que o mito da legalidade ou as premissas de justiça idealista possam triunfar sem enfrentar as forças conflitantes em ação na vida social; a todo tempo as metamorfoses, a resistência das baratas e os fantasmas da serpente, com sua plasticidade de formas e de forças, servem para lembrar que a história continua a operar sobrevivências e retornos, capazes de romper com a inércia e a precariedade do sentimento de segurança propiciado pelo mito da legalidade e de justiça idealista. 


\title{
Referências
}

\begin{abstract}
ADORNO, Theodor W. As estrelas descem à terra: a coluna de astrologia do Los Angeles Times - um estudo sobre superstição secundária. São Paulo: Editora Unesp, 2008.
\end{abstract}

ADORNO, Theodor W. Para a metacrítica da teoria do conhecimento: estudos sobre Husserl e as antinomias fenomenológicas. São Paulo: Editora Unesp, 2015.

AUERBACH, Erich. Mimesis: a representação da realidade na literatura ocidental. 5. ed. São Paulo: Editora Perspectiva S/A, 2004.

BARCELLONA, Pietro; DE GIORGI, Raffaele; NATOLI, Savaltore. Fine della storia e modo come sistema: tesi sulla post-modernità. Bari: Edizioni Dedado, 2003.

BOBBIO, Noberto. Jusnaturalismo e positivismo jurídico. São Paulo: Editora Unesp, 2016.

DIDI-HUBERMAN, Georges. A imagem sobrevivente: história da arte e tempo dos fantasmas segundo Aby Warburg. Rio de Janeiro: Editora Contraponto, 2013.

GINSBURG, Carlo. Medo, reverência, terror: quadro ensaios de iconografia política. São Paulo: Companhia das Letras, 2014.

GROSSI, Paolo. De la codificación a la globalización del derecho. Navarra: Editorial Aranzadi, 2010.

GROTIUS, Hugo. O direito da guerra e da paz. Ijuí: Editora Unijui, 2004.

FOUCAULT, Michel. Seguridad, territorio, población. Buenos Aires: Fondo de Cultura Económica, 2011.

FOSTER, Hal. O retorno do real. São Paulo: Editora Cosac Naify, 2014. FREUD, Sigmund. História de uma neurose infantil (o homem dos lobos). São Paulo: Companha das Letras, 2010. p. 13-160.

HEGEL, G.F.W. Fenomenologia do espírito. 9. ed. Petrópolis: Editora Vozes, 2014. 
HONNETH, Axel. Luta por reconhecimento: a gramática moral dos conflitos sociais. 2. ed. São Paulo: Editora 34, 2009.

JARRIGE, Fraçois. Le martyre de Jacquard ou le mythe de l'inventeur héroique (France, XIX siècle). Tracés - Revue de sciences humaines, [S.l.], n. 16, Lion, 2009. p. 99-117.

KAFKA, Franz. Metamorfose. São Paulo: Cia das Letras, 2000.

KAFKA, Franz. Um médico rural. São Paulo: Brasiliense, 1991.

LOEWITH, Karl. Racionalização e liberdade: o sentido da ação social. In FORACCHI, Marialice Mencarini; MARTINS, José de Souza (org.). Sociologia e sociedade: leituras de introdução à sociologia. Rio de Janeiro: LTD Editora, 1983. p. 143-162.

LOSURDO, Domenico. Hegel, Marx e a tradição liberal: liberdade, igualdade e Estado. São Paulo: Editora Unesp, 1998.

MACINTYRE, Alasdair C. Depois da virtude: um estudo da teoria moral. Bauru: Edusc, 2001.

MACINTYRE, Alasdair C. Teorías del derecho natural en la cultura de la modernidad avanzada. Doxa - Cuadernos de Filosofía Del Derecho, Madrid: Marcial Pons, n. 35, p. 513-526, 2013, p. 513-526.

NOBRE, Marcos. Reconstrução em dois níveis: um aspecto do modelo crítico de Axel Honneth. In: MELO, Rurion (coord.). A teoria crítica de Axel Honneth: reconhecimento, liberdade e política. São Paulo: Editora Saraiva, 2013. p. 11-54.

OLIVEIRA, Adeilson Luz de; OLIVEIRA, Francisco Cardozo.

Paradoxos e utopia na normatividade dos direitos humanos: a efetividade da proteção da pessoa e da cidadania na perspectiva material das relações de reconhecimento. In: CARDIN, Valéria da Silva Galdino; DEL'OLMO, Florisbal de Souza; FEITOSA, Maria Luiz Pereira de Alencar Mayer (coord.). Direito internacional dos direitos humanos I. Florianópolis, CONPEDI, 2014. p. 398-422. Disponível em: www.conpedi.org.br/ publicações. Acesso em: 16 abr. 2017. 
OST, François. Contar a lei: as fontes do imaginário jurídico. São Leopoldo: Editora Unisinos, 2005.

SASSEN, Saskia. Expulsões: brutalidade e complexidade na economia global. São Paulo: Editora Paz e Terras, 2016.

STRECK, Lênio Luiz. Desconstruindo os modelos de juiz: a hermenêutica jurídica e a superação do esquema sujeito-objeto. In: STRECK, Lênio Luiz; MORAIS José Luiz Bolzan de (org.). Constituição, sistemas sociais e hermenêutica. Porto Alegre: Livraria do Advogado Editora, 2008. p. 97-116.

WARBURG, Aby. Histórias de fantasmas para gente grande: escritos, esboços e conferências. São Paulo: Companhia das Letras, 2015.

WEBER, Max. Economia e sociedade. Brasília: Editora UNB, 2009. v. 1.

VERONESE, Josiane Rose Petry. O direito no século XXI: o que a fraternidade tem a dizer. In: VERONESE, Josiane Rose Petry; OLIVEIRA, Olga M. B Aguiar de; MOTA, Sergio Ricardo Ferreira (org.). $O$ direito no Século XXI o que a fraternidade tem a dizer. Estudos desenvolvidos no Programa de Pós-graduação em Direito da UFSC. Florianópolis: Editora Insular, 2016. p. 19-35.

Francisco Cardozo Oliveira é Pós-doutor pela UFSC. Doutor pela UFPR. Professor de Direito Civil na graduação e de Fundamentos do Direito e do Estado no Mestrado do Unicuritiba. Juiz de Direito no Tribunal de Justiça do Paraná.

E-mail:xikocardozo@msn.com

Endereço profisional: Rua Chile, n. 1.678, Rebouças, Curitiba, PR. CEP: 80220181.

Nancy Mahra de Medeiros Nicolas Oliveira é Mestre pela PUCPR. Especialista pela UFPR. Diretora da Ematra-IX. Juíza do Trabalho aposentada.

E-mail: nancynicolas@hotmail.com

Endereço profisional: Av. Vicente Machado, n. 320, Centro, Curitiba, PR. CEP: 80420-010. 